\title{
Trends in self-reported sleep duration and insomnia-related symptoms in Finland from 1972 to 2005: a comparative review and re-analysis of Finnish population samples
}

\author{
ERKKI KRONHOLM ${ }^{1}$, TIMOPARTONEN ${ }^{2}$, TIINA LAATIKAINEN ${ }^{2}$, \\ MARKKU PELTONEN ${ }^{2}$, MIKKO HÄRM ̈̈ ${ }^{3}$, CHRISTER HUBLIN ${ }^{3}$, \\ JAAKOKAPRIO ${ }^{2,4}$, ARJAR.ARO ${ }^{5}$, MARKKU PARTINEN ${ }^{6}$, MIKAEL \\ FOGELHOLM ${ }^{7}$, RAISA VALVE ${ }^{8}$, JUSSIVAHTERA ${ }^{9}$, TUULA OKSANEN ${ }^{9}$, \\ MIKA KIVIMÄKI ${ }^{9,10}$, MARKKU KOSKENVUO ${ }^{4}$ and HANNA SUTELA ${ }^{11}$ \\ ${ }^{1}$ The National Public Health Institute, Turku, ${ }^{2}$ The National Public Health Institute, Helsinki, ${ }^{3}$ Finnish Institute of Occupational Health, Helsinki, \\ ${ }^{4}$ Department of Public Health, University of Helsinki, Helsinki, Finland, ${ }^{5}$ Institute of Health Sciences, University of Southern Denmark, Esbjerg, \\ Denmark, ${ }^{6}$ Skogby Sleep Clinic, Rinnekoti Research Centre, Espoo, ${ }^{7}$ The UKK Institute for Health Promotion Research, Tampere, ${ }^{8}$ University of \\ Helsinki, Palmenia, Lahti, ${ }^{9}$ Finnish Institute of Occupational Health, Turku, Finland, ${ }^{10}$ International Centre for Health and Society, Department \\ of Epidemiology and Public Health University College, London, UK and ${ }^{11}$ Statistics Finland, Helsinki, Finland
}

Accepted in revised form 31 October 2007; received 30 July 2007

SUMMARY A hypothesis concerning habitual sleep reduction and its adverse consequences among general population in modern societies has received wide publicity in the mass media, although scientific evidence supporting the hypothesis is scarce. Similarly, there is an extensively distributed belief, at least in Finland, that the prevalence of insomniarelated symptoms is increasing, but evidence for this is even sparser. These issues are important because of the known increased risk of mortality and health risks associated with sleep duration deviating from 7 to $8 \mathrm{~h}$. To reveal possible trends in self-reported sleep duration and insomnia-related symptoms, we reanalyzed all available data from surveys carried out in Finland from 1972 to 2005. The main results were that a minor decrease of self-reported sleep duration has taken place in Finland, especially among working aged men. However, the size of the reduction (about 4\%) was relatively small, approximately 5.5 min per each 10 years during the 33 years' time interval under study. The proportion of $7 \mathrm{~h}$ sleepers has increased and, correspondingly, the proportion of $8 \mathrm{~h}$ sleepers has decreased, but the extreme ends of the sleep duration distribution remained unchanged. Tentative evidence suggesting an increase in insomnia-related symptoms among working aged population during the last 10 years was found. In conclusion, the Finnish data during the past 33 years indicate a general decrease in selfreported sleep duration of about $18 \mathrm{~min}$ and an increase of sleep complaints, especially among the employed middle-aged population.

KEYWORDS epidemiology, insomnia, long-term trends, sleep problems, sleep reduction

Correspondence: Erkki Kronholm, National Public Health Institute, Department of Health and Functional Capacity, Laboratory for Population Research, Turku, FI 20720, Finland. Tel.: + 358-2-3316718; fax: +358-2-331-6720; e-mail: erkki.kronholm@ktl.fi

\section{INTRODUCTION}

It is commonly believed that sleep duration in the population has declined gradually. However, sleep habits in the older times are largely unknown, as stated by the historian Roger Ekirch: '...such elementary matters as the time and length of 
slumber before the nineteenth century remain an enigma' (Ekirch, 2001). However, contrary to common beliefs, the amount of sleep in the preindustrial era may have not been so much longer than today. In 1574, an Italian physician pointedly distinguished slumber of 8-h duration according to 'common custom' from prolonged sleep in 'ancient time' as Hippocrates had advised, cited in (Ekirch, 2001). This attitude (towards the proper length of sleep) is expressed also in such aphorisms as 'Nature requires five, Custom takes seven, Laziness nine, And wickedness eleven', cited in (Ekirch, 2001). Thus, for centuries, sleeping 7-8 h seems to have been considered normative. According to Ekirch, until the close of the early modern era, Western Europeans experienced, on most evenings, two major intervals of sleep, bridged by up to an hour or more of quiet wakefulness (Ekirch, 2001). Also napping during the day was probably more common than today. During the past two centuries, the preindustrial segmented sleep pattern has been replaced by a consolidated nocturnal sleep in modern societies. A hypothesis has been proposed (and grown into a belief in the mass media) that the sleep pattern in modern societies continues to evolve in the direction of gradual reduction of the amount of sleep (Webb and Agnew, 1975).

In the United States, the self-reported modal sleep duration has been estimated to be about $8 \mathrm{~h}$ in the 1960s (Kripke et al., 1979; see also Jean-Louis et al., 2000; Schoenborn, 1986). Recent Gallup surveys have yielded estimates of about $7 \mathrm{~h}$ or even less (Bliwise et al., 1992; Jean-Louis et al., 2000; National Sleep Foundation, 2003). In children, historical accounts have suggested a reduction of about $1.5 \mathrm{~h}$ in the average sleep duration from the years 1910-11 to 1963 (Webb and Agnew, 1975). Students, in particular, have been considered a risk group exposed to sleep reduction (Hicks et al., 1989).

Although scientific evidence supporting the reduction hypothesis is insufficient, the belief has changed into an almost undisputable conventional wisdom stating that the "modern society is severely sleep deprived, and that this chronic state of deprivation has consequences on the persons and society' (Kryger, 1995). As a result, it is supposed that 'the pervasive role of excessive sleepiness in our society is becoming apparent' (Bonnet and Arand, 1995) and 'sleepiness and fatigue are becoming endemic in the population' (Ferrara and De Gennaro, 2001).

In parallel with the belief presented in the mass media concerning the reduction of sleep, a belief that the prevalence of insomnia and insomnia-related symptoms and fatigue are increasing gradually is also popular. However, this issue lacks empirical evidence to an even higher extent than the reduction hypothesis. The practically only existing evidence comes from the USA, suggesting that, while fatigue and tiredness in men may have increased between 1930 and 1980, there is no similar increase in self-reported sleep disturbances (Bliwise, 1996).

The importance of this issue from the public health perspective is emphasized by epidemiological studies showing that short self-reported sleep duration is a risk factor, predicting statistically increased mortality and ill-health
(Youngstedt and Kripke, 2004b). On the other hand, the same is true also for long sleep duration (Youngstedt and Kripke, 2004a).

However, there are factors exacerbating the clarification of these issues. Epidemiological studies from different countries have shown intercultural variation in self-reported sleep characteristics and their associations between other factors (e.g., associations between sleep duration and age or gender) (Groeger et al., 2004; Kronholm et al., 2006). In this respect, important results were found recently in a study among students from 24 countries (Steptoe et al., 2006). The sleep duration was shortest in Japanese students $(6.20 \mathrm{~h}$ in men and $6.09 \mathrm{~h}$ in women) and longest in Romanian (8.04 h and $7.72 \mathrm{~h}$, respectively) and Bulgarian ( $7.81 \mathrm{~h}$ and $8.00 \mathrm{~h}$, respectively) students. These differences clearly indicate that the results from different countries at varying points in time do not form a database from which inferences could be drawn on possible sleep duration reduction. Consequently, empirical data are needed from each country over a longer time span.

Irrespective of the viewpoint dominating in the mass media, there is no consensus in the scientific community on the issue of general sleep reduction in society and its possible consequences (Buysse, 2002; Dinges, 2004; Horne, 2004; Kripke, 2004). It is clear that long-term trends in self-reported sleep duration in different samples are likely to be confounded by several factors such as differences in study protocol and sampling, individual differences in economic status, and cultural differences (Harrison and Horne, 1995). An important argument is that, during the decades when sleep duration is assumed to have declined, the overall health in population has improved. Furthermore, there are no population-based data suggesting greater wellness or better performance among those sleeping longer than the current population mean (Jean-Louis et al., 2000). As emphasized by Groeger et al. (2004), with a few exceptions, data on the self-reported sleep duration tend to be based on small samples drawn from certain specific groups, and hence, the results are unlikely to be representative of the population as a whole.

To obtain as complete a picture as possible of the trends in self-reported sleep duration and insomnia-related symptoms in Finland over the last decades, we compiled and reanalyzed all available data from various surveys carried out in Finland between the years 1972 and 2005.

\section{METHODS}

Samples

For the purposes of this study, the following samples were reanalyzed:

The National FINRISK Study (FR): Seven independent cross-sectional population surveys were carried out in 1972 , 1977, 1982, 1987, 1992, 1997, and 2002. For each survey, an independent random sample was drawn from the Central Population Registry of Finland, covering the age range 2564 years. 
The Finnish Twin Cohort Study (FTC): This is the older part of the Finnish Twin Cohort of all Finnish twin pairs of the same gender born before 1958 and with both co-twins alive in 1975 (Kaprio and Koskenvuo, 2002; Kaprio et al., 1978). These twin pairs were selected from the Central Population Registry in 1974 by identifying all sets of persons with the same date of birth, the same surname at birth, the same community of birth and of the same gender. Biological twinship was confirmed through a questionnaire in the 1975 and inquiries of parish birth records. Three surveys covering the entire cohort have been carried out in 1975, 1981, and 1990.

The Fatigue in Job Study (FJS): A random sample from the Central Population Registry covering 5000 persons, aged 24 65 years, were approached in 1997 with a questionnaire, addressing stress, fatigue, and working conditions (Kalimo and Toppinen, 1997).

The Workers in Information Technology Study (WITS): A random sample of 5000 workers in the field of information technology (drawn from the membership registry of the relevant labor union) were approached with a postal questionnaire in 2001 (Härmä et al., 2002). After the exclusion of non-working persons and persons under 20 or over 69 years of age, the final sample consisted of 2334 persons $(46.7 \%$ of the original sample).

The Finnish Health 2000 Survey (FHS): The two-stage stratified cluster sampling frame by Statistics Finland comprised all adults aged 30 years and older. In addition, a sample of younger persons aged 18-29 years was drawn using the same sampling design. The survey was conducted in 2000.

The Finnish Public Sector Study (FPSS): This is an on-going prospective cohort study examining the health and well-being of employees in 10 municipalities and six district hospitals situated all around Finland (Kivimäki et al., 2007; Vahtera et al., 2006). Every 4 years, a postal survey questionnaire, addressing health and working conditions, is sent to all permanent and fixed-term (over 6 months) employees. The surveys carried out in 2000-01 and 2004 were reanalyzed in the present study.

The Health and Social Support in Finland Study (HeSSup): This is a longitudinal study on a population sample representative of the Finnish population in the following four age groups: 20-24, 30-34, 40-44, and 50-54 years at baseline (Korkeila et al., 2001). The baseline postal survey was conducted in 1998 and the follow-up survey in 2003.

The Health and Welfare in Adults in City of Tampere Study (HWAT): A random sample representative of the population aged 15 years and older in the City of Tampere (the second largest city in Finland with approximately 200000 habitants). The study was conducted in 2005.

Statistics Finland's Finnish Quality of Work Life Surveys (FQWLS): The surveys form a series of five independent random samples of employees. The participants were interviewed by Statistics Finland's interviewers in 1977, 1984, 1990, 1997, and 2003.

Thus, altogether nine independent studies or surveys forming 23 data points (samples) from 1972 to 2005 and covering a total of 251083 individuals were reanalyzed. The sample sizes and representativeness as well as participation rates are described in Table 1.

\section{Measures}

\section{Sleep duration}

The self-reported sleep duration was assessed by self-administered (usually postal) questionnaires. The questions used in different studies are shown in Table 2. For the purposes of this study, the answers were rounded to whole hours.

\section{Insomnia-related symptoms}

Across the studies, different questions were used to assess the prevalence of insomnia-related symptoms. Therefore, we decided to analyze only the FR survey samples (a time series of 33 years) and FQWLS survey samples (a time series of 26 years).

All of the seven postal questionnaires for the FR survey included the following insomnia-related question: 'During the past month, how often have you been bothered by insomnia?' Alternative answers were as follows: not at all; sometimes; and often. In addition, the use of hypnotics and the caffeine consumption were asked about.

All of the five interviews for the FQWLS survey included the following insomnia-related question: 'How often have you lately been bothered by difficulties in getting sleep or awakening during night?' Alternative answers modes were as follows: every day; a few times a week; around once a week; one or two times a month; less frequently; never.

\section{Analysis}

The mean values of self-reported sleep duration were calculated with $95 \%$ CI across the study samples first for the whole sample and then, separately for men and women. Then, to obtain a more detailed picture of possible differences (in the light of the reduction hypothesis) in the sleep duration distributions across the study samples, the proportions (\%) of short sleepers (6 h or less) as well as those sleeping $7 \mathrm{~h}$ or less were calculated by gender in young ( $\leq 30$ years) and adult working aged (30-65 years) participants. In addition, a regression equation (Eq. 1) was calculated using a General Linear Models (GLM) procedure with the self-reported sleep duration as a dependent variable and the time (sample year-1972) and the age (sample mean age-weighted mean of age across samples) as independent variables. Sample sizes were used as weights.

$$
\begin{aligned}
& \text { Self-reported sleep duration } \\
& \begin{array}{l}
=\text { constant }+\beta_{1}(\text { sample year }-1972) \\
\quad+\beta_{2}(\text { sample mean age }-42.21)
\end{array}
\end{aligned}
$$

For visual comparison, the prevalence of chronic and occasional insomnia-related symptoms (\%) among employees and working 


\begin{tabular}{|c|c|c|c|c|c|c|c|}
\hline \multirow[b]{2}{*}{ Sample } & \multirow[b]{2}{*}{ Year } & \multirow{2}{*}{$\begin{array}{l}\text { Original } \\
\text { sample }\end{array}$} & \multicolumn{3}{|c|}{ Participated } & \multirow{2}{*}{$\begin{array}{l}\text { Response } \\
\text { rate }(\%)\end{array}$} & \multirow[b]{2}{*}{ Representativeness of the sample } \\
\hline & & & All & Men & Women & & \\
\hline \multirow{7}{*}{$\begin{array}{l}\text { The National FINRISK Study } \\
\text { (FR) (independent samples) }\end{array}$} & 1972 & 13500 & 11870 & 5816 & 6054 & 87.9 & Participants $25-59$ years of age \\
\hline & 1977 & 13699 & 12155 & 5898 & 6257 & 88.7 & Participants $25-64$ years of age \\
\hline & 1982 & 11395 & 9347 & 4615 & 4732 & 82.0 & Participants $25-64$ years of age \\
\hline & 1987 & 7932 & 6479 & 3109 & 3370 & 81.7 & Participants $25-64$ years of age \\
\hline & 1992 & 7927 & 6051 & 2849 & 3202 & 76.3 & Participants $25-64$ years of age \\
\hline & 1997 & 11500 & 8341 & 4190 & 4151 & 72.5 & Participants $25-74$ years of age \\
\hline & 2002 & 13437 & 9580 & 4482 & 5098 & 71.3 & Participants $25-74$ years of age \\
\hline \multirow{3}{*}{$\begin{array}{l}\text { The Finnish Twin Cohort } \\
\text { (FTC) (the cohort was } \\
\text { followed up in } 1981 \text { and 1990) }\end{array}$} & 1975 & 34714 & 30917 & 15039 & 15878 & 89.1 & \multirow{3}{*}{$\begin{array}{l}\text { Representative of all like-sexed twin } \\
\text { pairs born before } 1958 \text {, but includes } \\
\text { also singletons (in } 1975 \text { survey only). } \\
\text { At baseline, the subjects were } \\
18-95 \text { years. The } 1990 \text { sample represents } \\
\text { persons } 33-60 \text { years of age }\end{array}$} \\
\hline & 1981 & 29208 & 24535 & 11860 & 12675 & 84.0 & \\
\hline & 1990 & 16179 & 12450 & 5674 & 6776 & 77.0 & \\
\hline Fatigue in Job Study (FJS) & 1997 & 5000 & 3298 & 1541 & 1757 & 66.0 & $\begin{array}{l}\text { Representative of working aged } \\
\text { ( } 24-65 \text { years) population }\end{array}$ \\
\hline $\begin{array}{l}\text { The Finnish Health } 2000 \\
\text { Survey (FHS) }\end{array}$ & 2000 & 9922 & 7262 & 3239 & 4023 & 73.2 & $\begin{array}{l}\text { Representative of general population aged } \\
30 \text { years and older and young adults } \\
18-29 \text { years of age }\end{array}$ \\
\hline $\begin{array}{l}\text { Workers in Information } \\
\text { Technology Study (WITS) }\end{array}$ & 2001 & 5000 & 2334 & 1653 & 681 & 46.7 & $\begin{array}{l}\text { Representative of workers in information } \\
\text { technology } 20-69 \text { years of age }\end{array}$ \\
\hline The Finnish Public Sector & 2001 & 71467 & 47023 & 9131 & 37888 & 65.8 & Longitudinal design 2001: participants \\
\hline Study (FPSS) & 2004 & 72842 & 47486 & 9363 & 38119 & 65.2 & $\begin{array}{l}\text { 17-65 years of age 2004: participants } \\
18-69 \text { years of age }\end{array}$ \\
\hline \multirow{2}{*}{$\begin{array}{l}\text { Health and Social Support in } \\
\text { Finland Study (HeSSup) }\end{array}$} & 1998 & 64797 & 25895 & 10628 & 15267 & 40.0 & \multirow{2}{*}{$\begin{array}{l}\text { Longitudinal design. Baseline } 20-54 \text { years } \\
\text { of age. Representative of general } \\
\text { population for this age range }\end{array}$} \\
\hline & 2003 & 24482 & 19626 & 7568 & 12058 & 80.2 & \\
\hline $\begin{array}{l}\text { Health and Welfare in Adults in } \\
\text { City of Tampere Study (HWAT) }\end{array}$ & 2005 & 3500 & 2255 & 911 & 1344 & 64.4 & $\begin{array}{l}\text { Representative of citizens of Tampere } \\
15-94 \text { years of age }\end{array}$ \\
\hline \multirow{5}{*}{$\begin{array}{l}\text { Statistics Finland: Finnish } \\
\text { Quality of Work Life } \\
\text { Surveys (FQWLS) }\end{array}$} & 1977 & 7500 & 5778 & & & 91.0 & \multirow{5}{*}{$\begin{array}{l}\text { Independent random samples of employees } \\
\text { interviewed in connection with } \\
\text { Labour Force Survey }\end{array}$} \\
\hline & 1984 & 5000 & 4502 & & & 89.0 & \\
\hline & 1990 & 5000 & 3502 & & & 85.0 & \\
\hline & 1997 & 3800 & 2979 & & & 78.3 & \\
\hline & 2003 & 5300 & 4104 & & & 77.4 & \\
\hline
\end{tabular}

Table 2 The questions used to assess self-reported sleep duration in different study samples

\begin{tabular}{lll}
\hline Question on sleep duration & Study & Year \\
\hline How many hours do you sleep in average per night? & The National FINRISK Study (FR) & 1972,1977 \\
How many hours do you usually sleep per 24 h? & The Finnish Twin Cohort (FTC) & $1975,1981,1990$ \\
& Health and Social Support in Finland (HeSSup) & 1998,2003 \\
& Fatigue in Job Study (FJS) & The Finnish Public Sector Study (FPSS) \\
How many hours do you sleep on average per $24 \mathrm{~h}$, & Workers in Information Technology Study (WITS) & 2001,2004 \\
including daytime naps? & The Finnish Health 2000 Survey (FHS) & 2001 \\
How many hours do you sleep in 24 h? & Health and Welfare in Adults in City of Tampere & 2000 \\
How many hours do you sleep on average per $24 \mathrm{~h} ?$ & Study (HWAT) & 2005 \\
\hline
\end{tabular}

aged (30-65 years) participants were calculated for the FR and FQWLS time series and plotted in the same figures.

\section{RESULTS}

\section{Sleep duration}

The mean self-reported sleep durations (for all, men, and women) across the study samples are shown in Fig. 1.
The GLM procedure yielded the following regression equation:

$$
\begin{aligned}
\text { Sleep duration }= & 7.627 \mathrm{~h}-0.00922(\text { sample year }-1972) \\
& -0.00805(\text { sample mean age }-42.21)
\end{aligned}
$$

In the model, the effect of sample year was statistically significant $(t$ value $=-4.70 ; P=0.0008)$ but the mean sample age was not statistically significant $(t$ value $=-1.28$; $P=0.228$ ). Thus, each 10 year increment during the last 

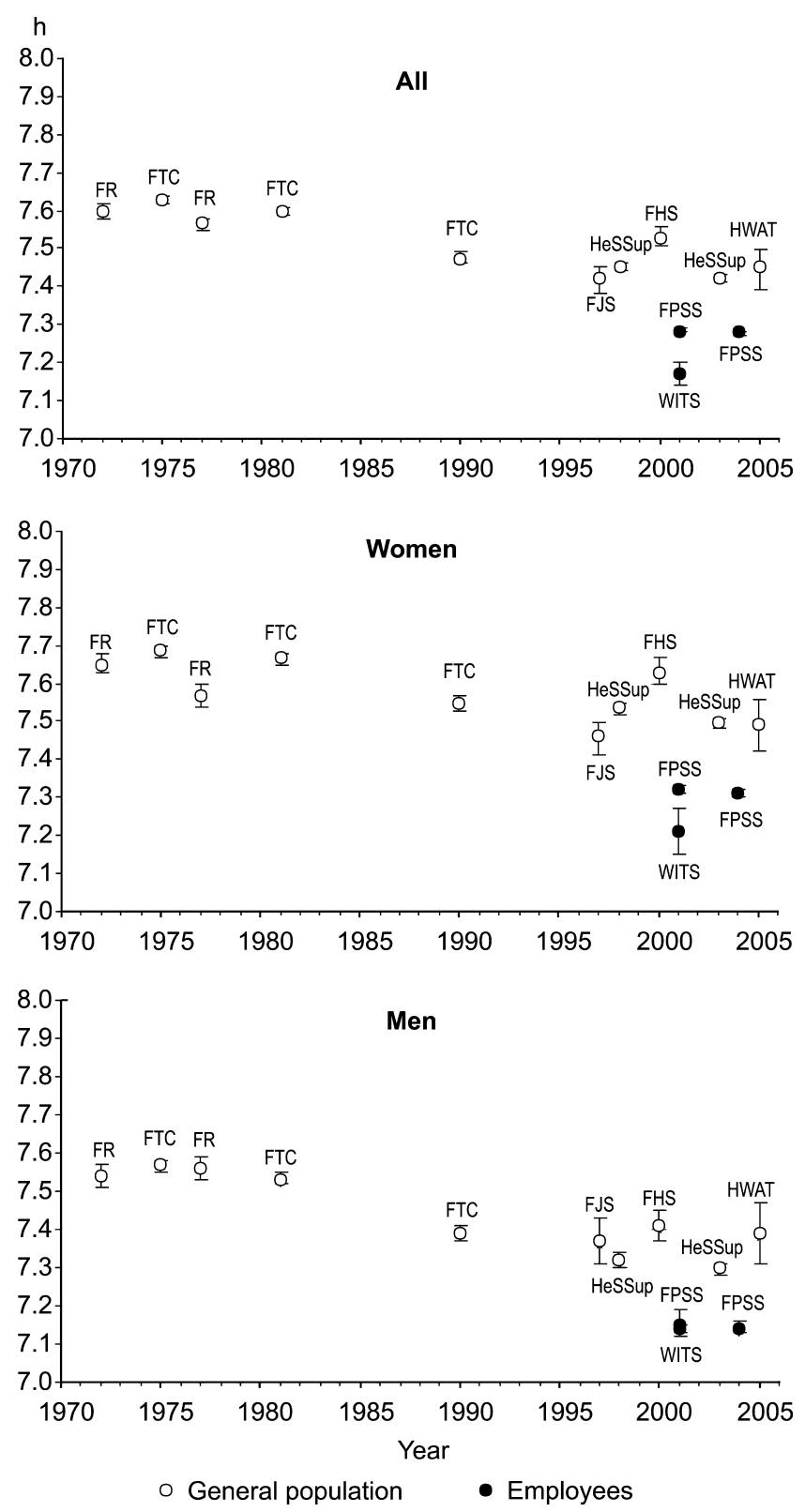

Figure 1. Mean self-reported sleep duration across the study samples. (Means and 95\% confidence intervals are shown. Empty circles: samples representing general population; black circles: samples representing employees.)

33 years in Finland decreased the mean self-reported sleep duration by $0.0922 \mathrm{~h}$, i.e., by $5.53 \mathrm{~min}$. Consequently, within the last 33 years the total change in average sleep duration was estimated to be $18.25 \mathrm{~min}$. The standard deviation of the sleep duration among the current adult general population was estimated to be 71.16 min based on the FHS. Consequently, in terms of the 'effect size' $(18.25 / 71.16)$ the magnitude of the reduction was 0.26 standard deviations, which can be considered to be rather small.

Although the oldest estimates of sleep duration in FR samples (1972 and 1977) are given 'per night', they are higher than any of the 'per 24 h' estimates, except for the FHS estimate for women in
2000, which was almost equal to the FR 1972 estimate. The estimates for men, in particular, seem to have decreased since the 1970s. At the first glance, these figures seem to provide support for the general sleep reduction hypothesis. However, the lowest estimates (WITS 2001, FPSS 2000-01, and 2004) are from samples representing the employed population, i.e., working individuals. Therefore, we repeated the analysis among the general population samples. The effect of sample year was again significant $(t$ value $=-5.20 ; P=0.0035)$, and the coefficient -0.00665 indicated self-reported sleep duration to have decreased by $3.99 \mathrm{~min}$ per each 10 year increment. It must be noted that, although significant, the differences between the sample means were relatively small. It is possible that even if the proportional changes at the group level (for example, from 8-h sleepers to 7-h sleepers) take place, the mean change at the population level remains relatively small. Therefore, we also analyzed the proportions of short sleepers ( $6 \mathrm{~h}$ or less and $7 \mathrm{~h}$ or less) in age and gender stratified sub-samples. These results are shown in Fig. 2.

As seen from Fig. 2, no consistent trend of increase in the number of short sleepers during 1972-2005 was seen in young men. In working aged (30-65 years) men, there was a clear trend of increase in the proportion of men sleeping $7 \mathrm{~h}$ or less. However, no such trend was found in the proportion of men sleeping $6 \mathrm{~h}$ or less. In young ( $<30$ years) women, there was not any clear trend in the proportion of short sleepers. In working aged (30-65 years) women, the situation was analogous to that of men of the same age. Thus, the hypothesis of general sleep reduction did not get undisputable support among young men or women. However, among working aged men, the mean proportion of short sleepers was greater across the 1997-2005 samples than across the 1972-1981 samples, giving some support for the hypothesis.

\section{Insomnia-related symptoms}

Chronic insomnia-related symptoms ('insomnia' was reported to bother 'often' in FR, and 'difficulties in getting sleep or awakening during night' were reported to occur 'every day' in FQWLS) were increased in the latest samples (FR 2002 and FQWLS 2003), when compared with the corresponding symptom prevalences in 1972 and 1977 (Fig. 3). Otherwise, no clear trend was found. However, a more consistent trend of an increasing prevalence was found in occasional insomniarelated symptoms (especially in employees, but in some degree also in FR samples) (Fig. 3).

According to the FR time series, the prevalence figures concerning the use of sleeping medicine at least once a week among adult population did not show any clear trend of increase; the figures varied between 4 and $6 \%$ from 1982 to 2002. Also, when the use of sleep medication was analyzed by groups with 'chronic insomnia-related symptoms' (50.6\% in 1972 and $52.5 \%$ in 2002) and 'occasional symptoms' (15.7\% in 1972 and $15.5 \%$ in 2002) and 'good sleepers' (2.1\% in 1972 and $2.4 \%$ in 2002), no time effect was observed in any of these groups in their use of sleeping medication across the FR time series. The caffeine consumption was not related to sleep 

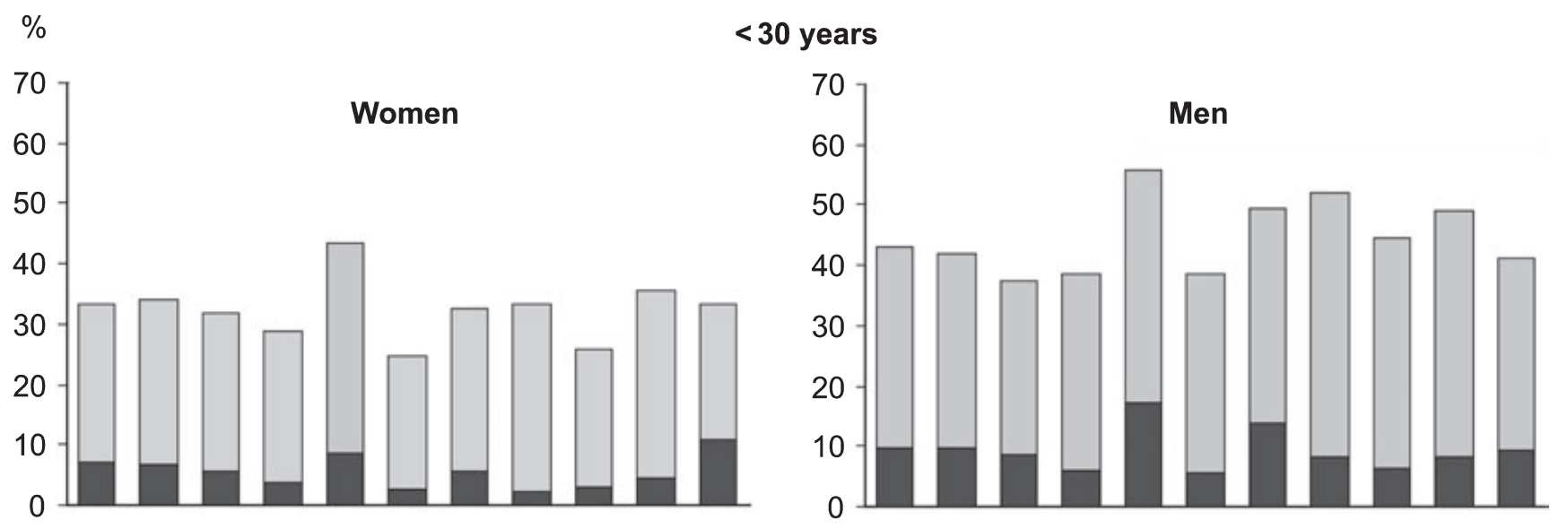

30-65 years

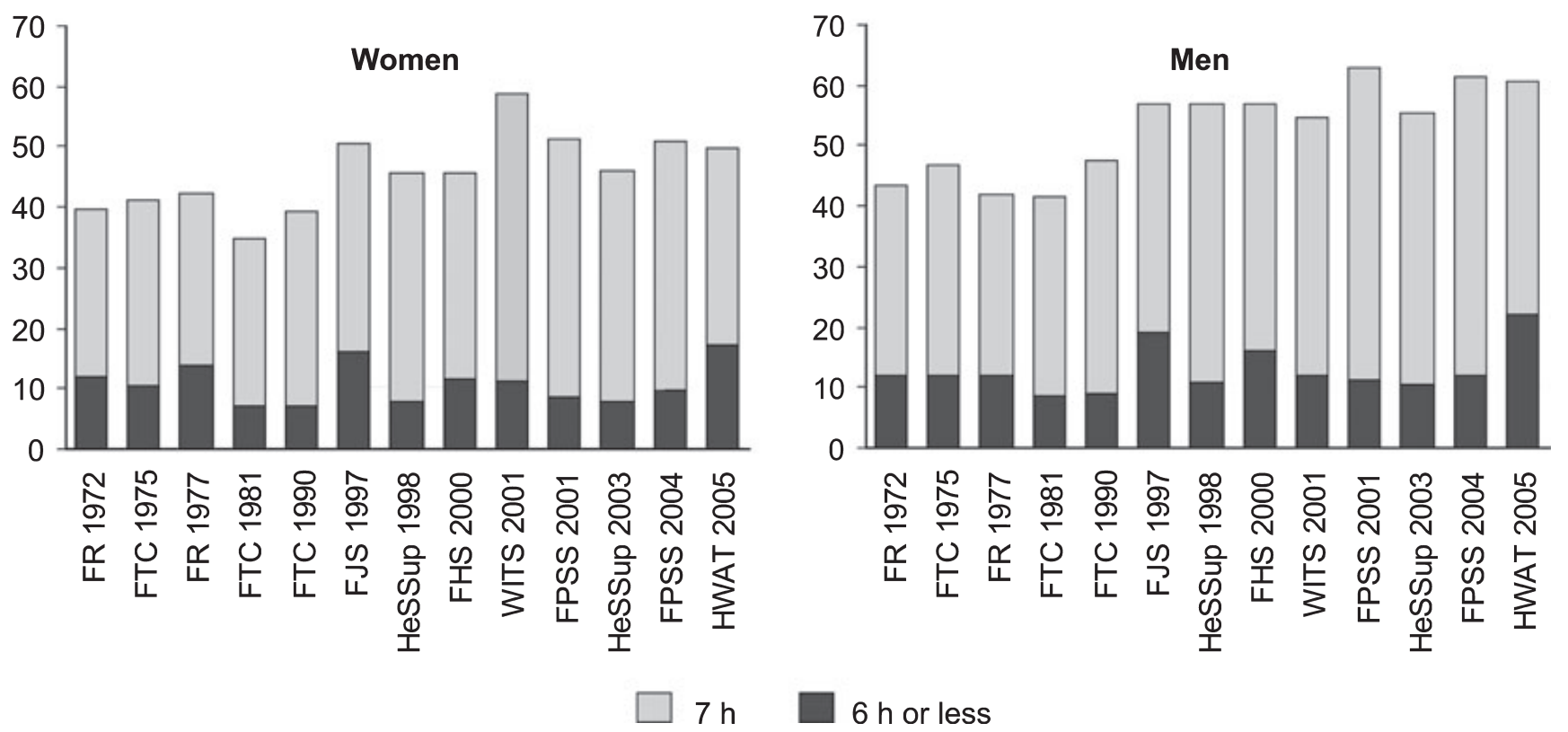

Figure 2. Proportions of individuals sleeping $7 \mathrm{~h}$ or less across the study samples. Top: women and men under 30 years. Bottom: women and men from 30 to 65 years. (Grey bars: sleep duration $7.0 \mathrm{~h}$; black bars: sleep duration $6.0 \mathrm{~h}$ or less. Note, the bars are additive. Together they indicate the proportion of persons who sleep $7 \mathrm{~h}$ or less.)

problems. In general, there was a decrease in the proportion of persons consuming more than six cups of coffee per day (from $50.6 \%$ in 1972 to $27.9 \%$ in 2002), and a corresponding increase in the proportion of persons consuming three to five cups of coffee per day (from $30.6 \%$ in 1972 to $55.4 \%$ in 2002). The proportion of those not drinking coffee at all also increased (from $4.9 \%$ in 1972 to $11.7 \%$ in 2002). However, these trends were not associated with the insomnia-related symptoms.

\section{DISCUSSION}

\section{Sleep duration}

The main result of our study was that, in terms of self-reported sleep duration across relatively large adult population samples over the past 33 years in Finland, a significant, albeit slight decrease was found. The decrease was revealed more clearly among men than among women. However, the size of the selfreported sleep duration decrease was relatively small, approximately 5.5 min per each 10 year interval. Behind this reduction, a shift between the proportions of 7- and 8-h sleepers in population was observed. The proportion of people sleeping $7 \mathrm{~h}$ per day has increased while the proportion of 8-h sleepers has decreased. This was seen most clearly among working aged men. Nevertheless, an important finding was that the proportions of the extreme ends of the sleep duration distribution (short sleepers sleeping $\leq 6 \mathrm{~h}$ and long sleepers sleeping $\geq 9 \mathrm{~h}$ ) remained unchanged. Consequently, our results suggest that in Finland during the past 33 years, a significant proportion of 8$\mathrm{h}$ sleepers may have reduced their sleep so that they now 


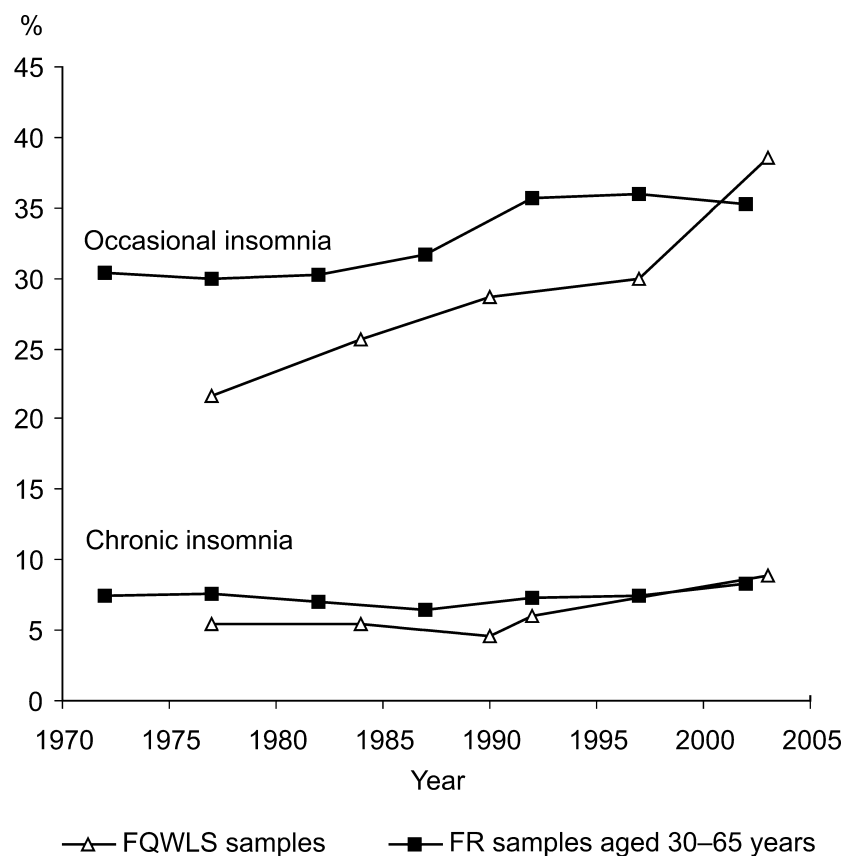

Figure 3. Prevalence of insomnia-related symptoms in two time series (FR: FINRISK studies, independent samples representing general population from 30 to 65 years of age; FQWLS: Finnish Quality of Work Life Surveys, independent samples representing employees). Occasional insomnia: insomnia-related symptoms occur 'sometimes' (FR) or 'a few times during a week or at least a few times during a month' (FQWLS). Chronic insomnia: insomnia-related symptoms occur 'often' (FR) or 'daily' (FQWLS).

belong to the group of $7-\mathrm{h}$ sleepers, but the extreme sleep duration groups (which are shown to be associated with increased health risks; for references see Youngstedt and Kripke, 2004b) seem to be quite stable. The most probable interpretation is that there are forces evolving in society that create pressures towards decreasing the behavioral sleep duration. However, these forces cannot be defined on the basis of our study. We might only speculate about the wide range of options such as changes in working life (e.g., shift work and otherwise irregular working hours, increased work demands), family demands, and life style (e.g., leisure-time physical activity, alcohol consumption, television, the internet, dietary changes) in Finnish society which may exert an impact on sleep duration towards a wake extension. The ability of an individual to adapt to these chances may vary. There is evidence suggesting that the choice of sleep duration may indicate inter-individual variation in the tolerance of sleep debt, especially in young adults (Klerman and Dijk, 2005). Nevertheless, individuals' ability to modulate their long-term behavioral sleep duration may be limited by homeostatic physiological and genetic factors (Dauviltiers et al., 2005; Franken et al., 2001; Linkowski, 1999; Partinen et al., 1983) and, therefore, dramatic changes may not occur at the population level. In addition, an unexplored possibility is that increasing public concern over sleep issues caused by mass media may have resulted in cognitive changes in attitudes or health awareness of the people concerning sleep which may, in turn, influence on their answering behavior when addressing sleep questionnaires.

The questions used to assess sleep duration in different samples were to some extent inconsistent. The oldest estimates of sleep duration in the FR samples (1972 and 1977) were given 'per night', thus excluding the possible effects of day-time naps on the overall 24-h sleep duration. These estimates may therefore slightly underestimate the diurnal sleep duration when compared with other studies. In an earlier study (Hyyppä and Kronholm, 1987), it was reported that, on the average, the exclusion of day-time naps decreases the average 24-h main sleep duration among adult Finnish population by approximately $16 \mathrm{~min}$. A general limitation of the present study is the fact that the estimates of sleep duration were based on self-reports. It is probable that the actual (physiological) sleep time is less than the subjectively defined sleep duration. In a relatively large study (Lauderdale et al., 2006) among 669 participants, sleep duration measured by means of a wrist actigraph was, on the average, about an hour shorter than the self-reported sleep duration over 3 days, and sleep was strongly associated with race, gender, and socioeconomic status. Sleep has been suggested to lie on the causal pathway between socioeconomic status and disease risk (Van Cauter and Spiegel, 1999). The relationship between self-reported and physiologically determined sleep duration is not fully understood. Thus, from the epidemiologic point of view, it is important to understand the whole spectrum of factors that influence the self-reported sleep duration to be able to interpret the meaning of trends in self-reported sleep duration. Recently, we found that sources of variance in self-reported sleep duration among general population in Finland were many; gender, marital status, occupational status, leisure-time physical activity, daytime tiredness or fatigue, and sleep-related factors (sleep disorders and use of sleeping medicine) each had an independent main effect on the sleep duration variance (Kronholm et al., 2006). The influence of age and selfperceived health were directed via several interactions with other predictors. Similarly, the influence of the level of education and other indicators of socioeconomic status, as well as the influence of alcohol consumption and smoking were directed via other predictors. However, the said factors accounted for only $16.4 \%$ of the total variance of sleep duration. Probably there are numerous physiological (both normal homeostatic and pathological conditions) and genetic factors (e.g., Dauviltiers et al., 2005; Linkowski, 1999; Partinen et al., 1983) underlying the main variance in sleep duration. If true, this suggests that external or lifestyle factors changing over time in society may, after all, not modulate individuals' long-term sleep duration to any greater extent.

\section{Insomnia-related symptoms}

We found some tentative evidence suggesting a possible increase in chronic insomnia-related symptoms among employed and working aged population over the past 10 years. This was supported by a more consistent trend of increase of 
occasional insomnia-related symptoms in the same population fraction. Thus, it may be that changes in working life have increased the employees' stress level which is reflected by increased insomnia-related symptoms (see for e.g., Kalimo et al., 2000; Åkerstedt et al., 2002). Interestingly, contemporary men reported increased levels of fatigue and tiredness, as compared with people in the post-Great Depression and preWorld War II era, although no increase in reported sleep disturbances was evident (cited by Ferrara and De Gennaro, 2001). However, (if true) these changes in insomnia-related symptoms may only have a slight effect on self-reported sleep duration. The seemingly self-evident association between insomnia-related symptoms and the consumption of sleeping medicines is also a more problematic issue than one would think at the first sight. In Finland, there has been a huge and quite linear increase in the consumption of hypnotics (ATC code N05C) from 1975 (18.80 year Defined daily dose (DDD)/1000 inhabitants/day) to 2005 (52.66 year DDD/1000 inhabitants/day) (National Agency for Medicines and Social Insurance Institution, 2006). Thus, the consumption has increased by 2.8 times within 30 years. However, according to the FR time series, the prevalence of the use of sleeping medicines and/or anxiolytics may not have changed in parallel. The estimate numbers may vary because of methodological differences (such as the phrasing of the alternative answers) but also because changes in the pharmaceutical industry's policies and in the clinical practice may have increased the consumption (per user) without a real increase in the number of users. The pharmaceutical industry has withdrawn small (10-30 pills) packages from the reimbursement (refunding) list, thus making it more economic for the patients to buy large packages containing, say, 100 pills at any given time. In some specific sections of the population, even the number of users may have increased. According to the statistics of the Social Insurance Institution of Finland (Kela), $3.8 \%$ of men and $5.2 \%$ of women in the age group 45-64 years were refunded for sleeping medication in 2000. In 2006, the corresponding figures were 5.9 and $8.6 \%$. However, according to the results from the FR time series, the prevalence figures concerning the use of sleeping medicine at least once a week among adult population do not show any clear trend of increase; the figures vary between 4 and 6\% from 1982 to 2002. Similarly, no evidence indicating a change in public attitude towards the use of sleeping medication was found at any level of insomnia-related symptoms during the last 33 years, meaning that the prevalence of the use of sleeping medication has been stable among chronic and occasional insomniacs, as well as in good sleepers. Obviously, more research is needed to clarify the associations between insomnia-related symptoms and the use of sleeping medicine.

Finland is the top country in the world in coffee drinking; over $90 \%$ of all people drink coffee (Pietinen et al., 1996). In the FR time series, a clear trend of decrease was found among persons consuming large amounts (six cups or more per day) of coffee, but a corresponding increase was found in moderate (three to five cups per day) coffee drinking. Still the proportion of persons not drinking coffee at all is relatively small among adult population (11.7\%). A study among seven European countries found that drinking six cups of coffee or more per day was associated with short self-reported sleep (Ohayon, 2004). The general cultural habit to drink coffee in Finland may explain that we did not find any association between insomnia-related symptoms and coffee drinking over the 33-year time span under study. Thus, at least in Finland, coffee drinking may not be indicative of daytime tiredness related to insomnia symptoms and it can not be used as an indirect measure to reveal possible changes in sleep problems.

\section{CONCLUSIONS}

In conclusion, our data over the past 33 years indicate a general decrease of approximately $18 \mathrm{~min}$ in self-reported sleep duration and an increase of occasional sleep complaints, especially among employed middle-aged population. The question remains whether these rather moderate changes in sleep duration and quality pose a threat of adverse societylevel consequences in terms of health risks, production efficiency, safety, or even mortality. This study does not allow us to draw any definitive conclusions in this respect. However, a reassuring finding may be that the proportional shares of short and long sleepers seem to be quite stable in general population. On the other hand, our earlier results also indicate the possibility that the health effects of short or poor sleep (e.g., increased risk of obesity, type 2 diabetes, depression, and hypertension) may be more prominent in certain specific working populations, such as employees with particularly long working hours (Kronholm et al., 2006) or those in information and communication technology sector. Other important subgroups for which the issue of insufficient sleep may be problematic include students and school children, but these groups were not included in the present study. Obviously, more studies are needed to clarify the possible adverse effects of decreased sleep duration and slightly increased insomniarelated symptoms in the modern society, especially among the most vulnerable subgroups.

\section{REFERENCES}

Åkerstedt, T., Knutsson, A., Westerholm, P., Theorell, T., Alfredsson, L. and Kecklund, G. Sleep disturbances, work stress and work hours: a cross-sectional study. J. Psychosom. Res., 2002, 53: 741748.

Bliwise, D. L. Historical change in the report of daytime fatigue [editorial]. Sleep, 1996, 19: 462-464.

Bliwise, D. L., King, A. C., Harris, R. B. and Haskell, W. L. Prevalence of self-reported poor sleep in a healthy population aged 50-65. Soc. Sci. Med., 1992, 34: 49-55.

Bonnet, M. H. and Arand, D. L. We are chronically sleep deprived. Sleep, 1995, 18: 908-911.

Buysse, D. Can sleep be bad for you? Can insomnia be good? Arch. Gen. Psychiatry, 2002, 59: 137-138.

Dauviltiers, Y., Maret, S. and Tafti, M. Genetics of normal and pathological sleep in humans. Sleep Med. Rev., 2005, 9: 91-100. 
Dinges, D. F. Sleep debt and scientific evidence (editorial). Sleep, 2004, 27: $1050-1052$.

Ekirch, A. R. Sleep we have lost: pre-industrial slumber in the British isles. Am. Hist. Rev., 2001, 106: 343-386.

Ferrara, M. and De Gennaro, L. How much sleep do we need? Sleep Med. Rev., 2001, 5: 155-179.

Franken, P., Chollet, D. and Tafti, M. The homeostatic regulation of sleep need is under genetic control. J. Neurosci., 2001, 21: 26102621.

Jean-Louis, G., Kripke, D. F. and Ancoli-Israel, S. Sleep and quality of well-being. Sleep, 2000, 23: 1115-1121.

Groeger, J. A., Zijlstra, F. R. H. and Dijk, D.-J. Sleep quantity, sleep difficulties and their perceived consequences in a representative sample of some 2000 British adults. J. Sleep Res., 2004, 13: 359-371.

Härmä, M., Kivistö, M., Kalimo, R. and Sallinen, M. Work demands, working times and sleep among information technology profession (in Finnish). Sitra Reports 22, Helsinki, 2002.

Harrison, Y. and Horne, J. A. Should we be taking more sleep? Sleep, 1995, 18: 901-907.

Hicks, R. A., Mistry, R., Lucero, K., Lee, L. and Pellegrini, R. The sleep duration and sleep satisfaction of college students: striking changes over the last decade (1978-1988). Percept. Mot. Skills, 1989, 68: 806.

Horne, J. Is there a sleep debt? Sleep, 2004, 27: 1047-1049.

Hyyppä, M. T. and Kronholm, E. (Eds) How does Finland sleep? (in Finnish) Kela, M. L.: 68, Turku, 1987.

Kalimo, R. and Toppinen, S. Work Related Fatigue in Finnish Working Aged Population (in Finnish). Finnish Institute of Occupational Health, Helsinki, 1997.

Kalimo, R., Tenkanen, L., Härmä, M., Poppius, E. and Heinsalmi, P. Job stress and sleep disorders: findings from Helsinki Herat Study. Stress Med., 2000, 16: 65-75.

Kaprio, J. and Koskenvuo, M. Genetic and environmental factors in complex diseases: the older Finnish twin cohort. Twin Res., 2002, 5: 358-365.

Kaprio, J., Sarna, S., Koskenvuo, M. and Rantasalo, I. The Finnish Twin Registry: formation and compilation, questionnaire study, zygosity determination procedures and research program. Prog. Clin. Biol. Res., 1978, 24B: 179-184.

Kivimäki, M., Vahtera, J., Elovainio, M., Virtanen, M. and Siegrist, J. Effort-reward imbalance, procedural injustice and relational injustice as psychosocial predictors of health: complementary or redundant models?. Occup. Environ. Med., 2007, 64: 659-665.

Klerman, E. B. and Dijk, D. J. Interindividual variation in sleep duration and its association with sleep debt in young adults. Sleep, 2005, 28: 1253-1259.

Korkeila, K., Suominen, S., Ahvenainen, J., Ojanlatva, A., Rautava, P., Helenius, H. and Koskenvuo, M. Non-response and related factors in a nation-wide health survey. Eur. J. Epidemiol., 2001, 17: 991-999.

Kripke, D. F. Do we sleep too much? Comment on Tamakoshi A; Ohno Y. Self-reported sleep duration as a predictor of all-cause mortality: results from the JACC study, Japan. Sleep 2004; 27: 13-14.

Kripke, D., Simons, R., Garfinkel, L. and Hammond, C. Short and long sleep and sleeping pills. Is increased mortality associated? Arch. Gen. Psychiatry, 1979, 36: 103-116.

Kronholm, E., Härmä, M., Hublin, C., Aro, A. R. and Partonen, T. Self-reported sleep duration in Finnish general population $J$. Sleep Res., 2006; 15: 276-290.

Kryger, M. H. Is society sleep deprived? Sleep, 1995, 18: 901.

Lauderdale, D. S., Knutson, K. L., Yan, L. J. L., Rathouz, P. J., Hulley, S. B., Sidney, S. and Liu, K. Objectively measured sleep characteristics among early-middle-aged adults - The CARDIA study. Am. J. Epidemiol., 2006, 164: 5-16.

Linkowski, P. EEG sleep patterns in twins. J Sleep Res, 1999, 8(Suppl. 1): 11-13.

National Agency for Medicines and Social Insurance Institution. Finnish Statistics on Medicines 2005. National Agency for Medicines and Social Insurance Institution, Helsinki, 2006.

National Sleep Foundation. Sleep in America Poll. National Sleep Foundation, URL http://www.sleepfoundation.org, 2003.

Ohayon, M. M. Interactions between sleep normative data and sociocultural characteristics in the elderly. J. Psychosom. Res., 2004, 56: 479-486.

Partinen, M., Kaprio, J., Koskenvuo, M., Putkonen, P. and Langinvainio, H. Genetic and environmental determination of human sleep. Sleep, 1983, 6: 179-185.

Pietinen, P., Vartiainen, E., Seppänen, R., Aro, A. and Puska, P. Changes in diet in Finland from 1972 to 1992: impact on coronary heart disease risk. Prev. Med., 1996, 25: 243-250.

Schoenborn, C. A. Health habits of U.S. adults, 1985: the "Alameda 7" revisited. Public Health Rep., 1986, 101: 571-580.

Steptoe, A., Peacey, V. and Wardle, J. Sleep duration and health in young adults. Arch. Intern. Med., 2006, 166: 1689-1692.

Vahtera, J., Pentti, J., Helenius, H. and Kivimaki, M. Sleep disturbances as a predictor of long-term increase in sickness absence among employees after family death or illness. Sleep, 2006, 29: 673-682.

Van Cauter, E. and Spiegel, K. Sleep as a mediator of the relationship between socioeconomic status and health: a hypothesis. Ann. N. Y. Acad. Sci., 1999, 896: 254-261.

Webb, W. B. and Agnew, H. W. Are we chronically sleep deprived? Bull. Psychon. Soc., 1975, 6: 47-48.

Youngstedt, S. D. and Kripke, D. F. Long sleep and mortality: have we been chasing the wrong tail? Sleep Med. Rev., 2004a, 8: 175-176.

Youngstedt, S. D. and Kripke, D. F. Long sleep and mortality: rationale for sleep restriction. Sleep Med. Rev., 2004b, 8: 159-174. 